\title{
A EFETIVIDADE DAS NORMAS FUNDAMENTAIS NO ÂMBITO DA AÇÃO CIVIL PÚBLICA: UM ENFOQUE NOS LITÍGIOS COLETIVOS À LUZ DO NOVO CÓDIGO DE PROCESSO CIVIL BRASILEIRO
}

THE EFFECTIVENESS OF FUNDAMENTAL STANDARDS IN THE FIELD OF PUBLIC CIVIL ACTION: A FOCUS ON COLLECTIVE LITIGATION IN THE LIGHT OF THE NEW CODE OF BRAZILIAN CIVIL PROCEDURE

Vanessa Mascarenhas de Araújo

Mestra em Direito Público pela Universidade Federal da Babia (UFBA). Especialista em Politica e Estratégia pela Universidade do Estado da Babia (UNEB) e Especialista em Direito Processual Civil pela Universidade Católica do Salvador (UCSAL)

jus.vma@gmail.com

\section{RESUMO}

O presente artigo tem como objetivo geral demonstrar a importância da efetividade das normas fundamentais - força normativa dos princípios - previstas na Parte Geral do Novo Código de Processo Civil brasileiro - CPC/2015 - na medida em que haja a adequação às especificidades do procedimento da ação civil pública, notadamente, no que tange à representatividade adequada. Mediante pesquisa bibliográfica, o trabalho se desenvolve nos seguintes tópicos: ação civil pública como procedimento especial, breve histórico, objeto tutelado, litígios coletivos; as normas fundamentais do CPC/2015; os litígios coletivos e a efetividade das normas dos direitos fundamentais. Adota-se, aqui, o entendimento de que a ação civil púbica é um procedimento especial em decorrência não tão somente em razáo do objeto tutelado - os direitos coletivos latu sensu, mas também em decorrência dos litígios coletivos que são apresentados ao Estado-juiz. Não obstante a tais peculiaridades encontradas neste procedimento especial, os envolvidos neste, em destaque, a Defensoria Pública na promoção dos direitos dos necessitados, devem observar e aplicar o diploma processual civil pátrio, sobretudo, no que diz respeito às normas fundamentais.

Palavras-chave: Ação Civil Pública. Litígios Coletivos. Normas fundamentais. Força normativa dos princípios. Novo Código de Processo Civil. 


\begin{abstract}
The objective of this monographic work is to demonstrate the importance of the effectiveness of the fundamental norms - normative force of the principles - foreseen in the General Part of the new Brazilian Civil Procedure Code - CPC / 2015 - insofar as there is the adequacy to the specificities of the public civil action, especially with regard to adequate representation. Through a bibliographical review, the work is developed in the following topics: public civil action as special procedure, historical brief, protected object, collective litigation; the fundamental rules of the new civil procedure code; collective litigation and the effectiveness of fundamental rights norms. It is hereby adopted the understanding that the public civil action is a special procedure due not only to the collective rights latu sensu that has as object of tutelage, but also as a result of the collective litigation that is presented to the State-judge; however, that such an argument can not be sustained to the point of removing the discipline of the collective proceeding by the civil procedure code.
\end{abstract}

Keywords: Public Civil Action. Collective litigation. Fundamental rules. Normative force of principles. New Code of Civil Procedure.

Data de submissão: 27/02/2018

Data de aceitação: 21/07/2019

\title{
SUMÁRIO
}

INTRODUÇÃO 1. PROCEDIMENTO ESPECIAL E A AÇÃO CIVIL PÚBLICA: A ESSÊNCIA DOS PROCEDIMENTOS ESPECIAIS 1.1. Breve histórico da ACP no âmbito do direito processual brasileiro. Fundamento no ordenamento jurídico pátrio 1.2. A ACP como procedimento especial: objeto tutelado, litígios coletivos e suas especificidades 2. AS NORMAS FUNDAMENTAIS E O NOVO CÓDIGO DE PROCESSO CIVIL. 2.1. A natureza jurídica das normas fundamentais 2.2. A teoria da força normativa dos princípios e o Novo Código de Processo Civil 3. OS LITÍGIOS COLETIVOS E A EFETIVIDADE DAS NORMAS FUNDAMENTAIS DO PROCESSO CIVIL. CONCLUSÃO 


\section{INTRODUÇÃO}

Ao ter como enfoque deste trabalho monográfico os litígios coletivos em um cenário processual no qual se pretende verificar a efetividade das normas fundamentais estabelecidas no novo diploma processual civil brasileiro - Código de Processo Civil de 2015, coubenos, primeiramente, remeter aos estudos da ação civil pública - instrumento jurídico processual que se entende por procedimento especial em decorrência da necessidade de adequação do processo à tutela dos direitos transindividuais - os direitos coletivos latu sensu. Em verdade, deve-se ir além da adequação às categorizaçóes destes novos direitos: faz-se necessário adequar os atos e os institutos processuais inerentes à ação civil pública às peculiaridades dos litígios coletivos.

O diploma processual civil brasileiro de 1973 atendia à solução de conflitos de cunho, essencialmente, individual. Com o advento do novo código processual em 2015, não significar afirmar, no entanto, que houve uma disciplina detalhada e específica no que diz respeito aos processos coletivos, ou, então, que trate, em um capítulo específico, do procedimento da açẫo civil pública. Na verdade, o Código de Processo Civil é aplicado subsidiariamente ao microssistema do processo coletivo; mas, com a inclusão da Parte Geral, especificamente no tocante à inclusão das normas fundamentais do processo civil, pode-se afirmar que tais normas, indubitavelmente, devem ser observadas e concretizadas tanto nas relaçôes jurídicas processuais individuais, quanto nas relações jurídicas processuais coletivas.

O legislador, ao prevê no artigo $8^{\circ}$, por exemplo, que, ao aplicar o ordenamento jurídico, o juiz atenderá aos fins sociais e às exigências do bem comum, resguardando e promovendo a dignidade da pessoa humana e observando a proporcionalidade, a razoabilidade, a legalidade, a publicidade e a eficiência, impóe o dever ao Estado-juiz de efetivar a dignidade humana, por conseguinte, os direitos fundamentais, em qualquer cenário processual, seja este composto pela estrutura individual, seja ele composto pela estrutura coletiva. Mas, se tais estruturas são diversas, demandaria o litígio coletivo de uma tutela jurisdicional específica, compatibilizando com o que estabelecem as normas fundamentais elencadas no novo código de processo civil brasileiro?

Dessa forma, mediante revisão bibliográfica, o presente artigo tem como objetivo geral demonstrar a necessidade de adequação no que diz respeito à aplicação das normas fundamentais do processo civil às especificidades da ação civil pública, notadamente, no que se refere à representatividade adequada, de modo a alcançar a efetividade dos direitos fundamentais que estáo sendo violados ou na eminência de serem, o que acaba por resultar no estopim do litígio coletivo.

Para o desenvolvimento de tal propósito, o trabalho está divido em quatro tópicos. O primeiro versa sobre a ação civil pública como procedimento especial, onde se enfatiza a essência do referido procedimento e, posteriormente, apresenta-se um breve histórico da ação civil pública no âmbito do direito processual brasileiro, objeto tutelado, litígios transindividuais e suas especificidades; o segundo busca, de cunho geral, tratar da disciplina 
das normas fundamentais estabelecidas no Código de Processo Civil 2015, apresentando os respectivos dispositivos, a sua natureza jurídica e a relação com a Teoria Normativa dos Princípios.

No terceiro tópico, trata-se da adequação de tais normas fundamentais ao procedimento da ação civil pública para a eficácia da resolução do litígio coletivo, de modo a ressaltar a importância das instituiçóes públicas, com destaque para a Defensoria Pública da União, na atividade desta adequação; e, por fim, a conclusão, no sentido de afirmar a necessidade da aplicação das normas fundamentais adaptadas às peculiaridades da ação civil pública de modo a garantir a efetividade dos direitos fundamentais envolvidos no litígio coletivo.

\section{PROCEDIMENTO ESPECIAL E A AÇÃO CIVIL PÚBLICA: A ESSÊNCIA DOS PROCEDIMENTOS ESPECIAIS}

No âmbito da ciência dogmática do direito processual civil brasileiro, bem como no âmbito epistemológico característico da Teoria Geral do Processo, ao ter como objeto de estudo os procedimentos especiais - com o escopo de apontar o seu conceito, e, por conseguinte, as suas peculiaridades-, cabe destacar, primeiramente, qual critério doutrinário foi considerado neste artigo para fins de determinar se um procedimento é, ou náo, especial. Antes, sobretudo, cabe-nos conceituar procedimento.

$\mathrm{Na}$ doutrina processual civil tradicional, tem-se como procedimento a forma pela qual o processo reveste-se, estando associado a um conjunto de atos jurídicos processuais; a forma pela qual as partes atuam no processo; aquele que se desenvolve sem o contraditório; aquele constituído por sequências de atos, envolvendo os requisitos de admissibilidade e os princípios processuais. ${ }^{1}$ Tem-se o procedimento como a exteriorização do processo ${ }^{2}$.

Nas liçóes de Antonio Carlos Marcato, processo e procedimento mostram-se inconfundíveis, sendo aquele o instrumento através do qual se opera a jurisdição, enquanto que este representa o meio extrínseco de instauração, desenvolvimento e extinção do processo. ${ }^{3}$

$\mathrm{Na}$ doutrina processual civil hodierna, ao lado do entendimento tradicional apontado, destaca-se o conceito de procedimentosimilar ao conceito de processo, o que se faz neces-

\footnotetext{
1 Tais entendimentos explanados acerca do conceito de procedimento são adotados, a exemplo, por DINAMARCO, Cândido Rangel (A instrumentalidade do processo, vol. 1, $3^{\mathrm{a}}$ ed., rev. e atual, São Paulo: Editora Malheiros, 1993, p. 126-137); ALVIM NETTO, José Manuel Arruda. (Manual de Direito Processual Civil. 8a ed. São Paulo: Revista dos Tribunais, 2003, 1 v, p. 110, 140 e 546.; FAZZALARI, Elio. (Instituzioni di Diritto Processuale. 8a ed. Padova: CEDAM, 1996, p. 82 e 83).

2 Destacam o caráter finalístico do processo, enquanto entende-se por procedimento a sua exteriorização: MARQUES, José Frederico. Manual de Direito Processual Civil. Saraiva: São Paulo: 1974,1 v, p. 8; ALVIM NETTO, José Manuel Arruda. Manual de Direito Processual Civil. 8 ed. São Paulo: Revisa dos Tribunais, 2003, 1 v., p. 110, 140 e 546; WAMBIER, Luiz Rodrigues. Sentença Civil: Liquidação e Cumprimento. 3 ed. São Paulo: Revista dos Tribunais, 2006, p. 87-90; WAMBIER, Teresa Arruda Alvim. Nulidade do processo e da sentença. 6 ed. Sáo Paulo: Revista dos Tribunais, 2007, p. 27.
}

3 MARCATO, A. C. Procedimentos especiais, 1994, p. 209. 
sário remontar ao peculiar entendimento de Paula Sarno Braga: "É a tutela jurisdicional visada [...] que pode ser obtida por meio de procedimentos (e, pois, processos, sinônimos que sáo) diversos, a depender das peculiaridades e necessidades que existam em torno do direito material a ser tutelado." " Em verdade, o processo é composto por atos procedimentais, que, necessariamente, hão de se concretizar para o desenvolvimento do exercício do poder jurisdicional; e ao tratar de procedimentos, seja comum, seja especial, faz-se necessário remeter às diversas maneiras pelas quais, em conjunto, irão estabelecer a "forma de encadeamento dos atos do processo". 5

Conforme destaca José Joaquim Calmon de Passos, o procedimento especial é justificável em decorrência da "absoluta necessidade de se atender a algo tão específico que seria disfuncional e até lesivo adotar-se na sua inteireza o procedimento ordinário (procedimento por excelência)" ". Dessa forma, verifica-se a sua notória excepcionalidade em relação ao procedimento ordinário, que não seria adequado para a tutela de determinado(s) direito(s), embora caracterizado como o mais solene dos procedimentos. ${ }^{7}$

Não se utiliza, aqui, o critério que diz respeito a uma análise comparativa entre procedimentos, ou seja, identificar o procedimento especial em relação a um determinado procedimento comum, sendo aquele criado pelo legislador por uma questão de celeridade processual em relação a este ${ }^{8}$. Mediante este critério, a ação civil pública, por exemplo, não se equivale a um procedimento específico, o que a tornaria não um procedimento especial, mas, o próprio procedimento comum para a tutela dos direitos coletivos lato sensu?

Trata-se, neste artigo, identificar o procedimento especial em decorrência das suas pe-

4 BRAGA, P. S. Norma de processo e norma de procedimento - o problema da repartição de competência legislativa no Direito constitucional brasileiro. 2015, p. 142.

5 Nesse sentido: VIANA, Vasconcelos Juvêncio In: Aspectos relevantes dos procedimentos especiais - Revista Dialética de Direito Processual Civil (RDDO), n. 26, maio, 2005, p. 77 - ao tratar de procedimentos - comuns e especiais - refere-se às diferentes maneiras pelas quais podemos combinar a forma de encadeamento doas atos do processo.

6 PASSOS, J. J. C. Teoria geral dos procedimentos especiais. Procedimentos especiais na legislação extravagante, 2003, p. 4.

7 Conforme destaca VIANA, Vasconcelos Juvêncio In: Aspectos relevantes dos procedimentos especiais - Revista Dialética de Direito Processual Civil (RDDO), n. 26, maio, 2005, p. 77 - o procedimento comum ordinário constitui o standard básico; sendo o mais solene dos demais procedimentos, com mais fases, prestando-se a um volume maior de demandas. Nesse sentido, FABRÍCIO, Adroaldo Furtado, in "Comentários do Código de Processo Civil, vol. VIII, Rio de Janeiro: Editora Forense, 1980, p. 4 - o procedimento comum serve ao volume maior e principal das causas, às situaçôes mais frequentes e destituídas de peculiaridades justificadoras de um tratamento diferenciado.

$8 \quad$ Conforme destaca VIANA, Vasconcelos Juvêncio In: Aspectos relevantes dos procedimentos especiais - Revista Dialética de Direito Processual Civil (RDDO), n. 26, maio, 2005, p. 74. - diante da pergunta: "Qual a razão para previsão legal de certos procedimentos especiais", tenderíamos a ficar "tentados a responder que os mesmos existem ante uma necessidade prática de tutela jurisdicional mais rápida em certas situações do direito material."

$9 \quad$ Nesse sentido, Fredie Didier Jr. e Hermes Zaneti Jr destacam que, o Direito processual coletivo brasileiro "não se preocupou em construir modelos procedimentais adaptáveis às peculiaridades dos conflitos coletivos. É como se qualquer tipo de conflito pudesse tramitar, adequadamente, pelo mesmo e único modelo de procedimento comum, regulado pela Lei n.o 7.347/1985.", In: Curso de Direito Processual Civil, v.4, $10^{a}$ ed., rev., atual., e ampl., Salvador: JusPodivm, 2016, p. 83. 
culiaridades, notadamente, em relação ao objeto a ser tutelado, que conduz ao legislador criar técnicas processuais específicas que se adequem à tutela deste objeto - já nesse sentido, tem-se a ação civil pública como um procedimento especial em razão da tutela daqueles direitos: "o procedimento assume a condição de conduto para a participação, otimizando a participação do povo na reivindicaçáo dos direitos fundamentais e na gestão da coisa pública." 10

Nas lições de Humberto Theodoro Jr., o procedimento é, justamente, "a maneira de estipular os atos necessários e de concatená-los, de forma a estabelecer o iter a ser percorrido pelos litigantes e pelo juiz ao longo do desenrolar da relação processual."11

Nota-se que, a existência de um procedimento especial está associada, necessariamente, a um determinado direito material, objeto a ser tutelado mediante um processo/procedimento adequado; logo, as regras processuais/procedimentais devem guardar uma relação direta e proporcional com as regras de direito material. ${ }^{12}$

O que se especializa, na verdade, é o momento satisfativodo processo/procedimento momento da efetividade da tutela jurídica certificada como devida pelo poder jurisdicional exercida pelo Estado-juiz: “é essa especialidade que, associada ao princípio da adstriçáo do juiz ao pedido ou, melhor dizendo, ao thema decidendum, pode excepcionalmente reclamar certos ajustamentos na postulação ou na instrução". ${ }^{13}$

Nesse sentido, pode-se afirmar que, a essência dos procedimentos especiais encontra-se no direito material a ser tutelado, cujo processo/procedimento deve ser realizado de forma adequada, a fim de atingir a sua efetividade, notadamente, no que se refere aos direitos fundamentais $^{14}$ - a exemplo do que ocorre com a ação civil pública.

Em que pese Fredie Didier Jr. e Hermes Zaneti Jr. apontarem esta espécie de ação coletiva como procedimento comum ${ }^{15}$, estes reconhecem que, o "princípio do devido processo legal coletivo impóem que se construa um processo adequado às peculiaridades do caso

\footnotetext{
10 MARINONI, L. G. ARENHART, S. C. Procedimentos especiais, 2012.

$11 \quad$ THEODORO JR., H. Curso de Direito Processual Civil, 2016, p. 38.

12 Conforme José Miguel Garcia de Medina e Fábio Caldas de Araújo destacam: "a existência de um direito material implica automática correlação, no plano do processo, de procedimento adequado. Não sendo assim, se estaria diante de situação paradoxal: o direito material seria previsto abstratamente, mas seria irrealizável concretamente.” In: MEDINA, José Miguel Garcia. et al (coords.) Processo civil moderno - Procedimentos cautelares e especiais, v. 4, São Paulo: Editora Revista dos Tribunais, 2009. Também nesse sentido, Arruda Alvim, Tratado de direito processual civil, vol. 1, n. 4.7.6, p. 259; Carlos Alberto Alvaro de Oliveira, Os direitos fundamentais à efetividade e à segurança em perspectiva dinâmica, Repro, vol. 155, jan. 2008.

13 PASSOS, J. J. C. Teoria geral dos procedimentos especiais. Procedimentos especiais na legislação extravagante, 2003, p. 5.

14 No tocante aos direitos fundamentais, Rober Alexy (Teoria dos direitos fundamentais, p. 473) destaca que, as normas de procedimento devem ser criadas de modo que o resultado seja, "com suficiente probabilidade e suficiente medida", adequada/conforme aos direitos fundamentais.

15 Fredie Didier Jr. e Hermes Zaneti Jr (Curso de Direito Processual Civil, vol. 4, 10a ed., rev., ampl. e atual., Salvador: Editora Juspodivm, 2016, p. 83) afirmam que o direito processual coletivo brasileiro não se preocupou em construir modelos procedimentais adaptáveis às peculiaridades dos conflitos coletivos: "É como se qualquer tipo de conflito pudesse tramitar, adequadamente, pelo mesmo e único modelo de procedimento comum, regulado pela Lei n. 7.347/1985”.
} 
concreto", haja vista que um procedimento adequado apenas previsto no plano legislativo, com menção à Lei n. ${ }^{\circ}$ 7.347/1985, não concretiza de forma plena, em tese, o princípio da adequação. Ademais, reconhecem que, o processo coletivo exige regramento próprio, devendo acomodar-se às suas respectivas peculiaridades, tais como, competência, legitimidade, coisa julgada, intervenção de terceiro, execução, bem como reconhecem o avanço da legislação brasileira em relação ao regramento próprio e "geralmente bem adequado" nos referidos aspectos. ${ }^{16}$

Tais peculiaridades da ação coletiva, em específico, da ação civil pública, permitem identificá-la como um tipo de procedimento especial, que, ao contrário do procedimento comum, está voltado à determinada situaçáo específica - a tutela dos direitos coletivos lato sensu - que, por sua vez, merece uma prestaçáo da tutela jurisdicional adequada. ${ }^{17}$

É da própria natureza das coisas que a forma se ajuste e se harmonize à substância ${ }^{18}$, não podendo ser diferente no âmbito do direito processual coletivo; o que se faz imperioso amoldar o processo/procedimento - no caso, a açáo civil pública - às peculiaridades tanto do direito subjetivo material a ser por ele tutelado, quanto do litígio a ser levado ao poder jurisdicional.

\subsection{Breve histórico da ACP no âmbito do direito processual brasileiro. Fundamento no ordenamento jurídico pátrio}

No tocante à análise do processo coletivo à luz do direito processual brasileiro ${ }^{19}$, seja através do CPC/1973, seja através do CPC/2015, devem ser consideradas as regras e princípios dispostos na lei processual que podem ser utilizados no âmbito da tutela coletiva, haja vista o Código de Processo Civil (tanto o de 1973, quanto o de 2015) náo estabelecer um procedimento próprio, ditando suas regras e peculiaridades, para o processo em comento, o qual foi consolidado com o advento da Lei da Ação Civil Pública (Lei n. ${ }^{\circ}$ 7.347/85) ${ }^{20}$, posteriormente, aperfeiçoado com o advento do Código da Defesa do Consumidor (Lei

\footnotetext{
16 DIDIER JR, F. e ZANETI JR., H. Curso de Direito Processual Civil, 2016, p. 83.

17 Conforme se depreende das liçôes de Giuseppe Chiovenda (Instituzioni di diritto processuale civile, $\mathrm{v}$. 1, n. 16, p. 54), os procedimentos especiais atendem ou à particularidade das formas admitidas para certos grupos de relaçóes jurídicas isoladas, ou, então, à particularidade da cognição.

18 THEODORO JR., H. Curso de Direito Processual Civil. vol. II - Procedimentos especiais, 2016, p. 39.

19 Conforme destaca Humberto Dalla Bernardinha de Pinho: "O direito processual brasileiro, originalmente filiado ás tradiçôes dos ordenamentos de linha romano-germânica, foi concebido em bases eminentemente individualistas, refletindo a mentalidade e as necessidades da sociedade daquela época”. (Direito Processual Civil Contemporâneo, São Paulo: Saraiva, $5^{a}$ ed., p. 709).

20 Conforme ressaltam José Miguel Garcia Medina e Fábio Caldas de Araújo (in Processo civil moderno Procedimentos cautelares e especiais, v. 4, São Paulo: Editora Revista dos Tribunais, 2009, p. 366), a Lei de ACP foi precedida apenas pela Lei da Açáo Popular (Lei n. ${ }^{\circ}$ 4.717/1965) quanto à tutela dos direitos coletivos; e seu objeto central reside na proteçáo dos interesses difusos e coletivos, mediante a previsão de um mecanismo processual peculiar para a prestação da tutela jurisdicional adequada, incluindo os individuais homogêneos mediante interpretaçáo extensiva do art. $1^{\circ}$ da Lei 7.347/1985, em virtude do art. 21 da LACP e no art. 117 do CDC.
} 
n. ${ }^{\circ} 8.078 / 90$ ) no que se refere à tutela dos direitos coletivos, difusos e os direitos individuais homogêneos (direitos fundamentais da terceira dimensão - de titularidade coletiva e difusa, os transindividuais, além dos individuais homogêneos), estando previsto, além na Constituição Federal/1988, nas demais leis infraconstitucionais (ECA, Estatuto do Idoso, Lei Maria da Penha, Estatuto da pessoa com deficiência, dentre outras).

Pode-se dizer que, a Lei de Ação Civil Pública teve como fonte originária o art. $14, \$ 1^{\circ}$, da Lei n. ${ }^{\circ}$ 6.938/8, que estabelece que, o Ministério Público da União e dos Estados terá legitimidade para propor ação de responsabilidade civil e criminal, por danos causados ao meio ambiente.

Conforme bem destaca Marcelo Abelha Rodrigues, a expressão ação civil pública designa o procedimento, o método, o conjunto de regras processuaisque estão estabelecidas na Lei n. ${ }^{\circ} 7.347 / 85$ e são aplicadas à relação jurídica processual instaurada por uma determinada demanda coletiva.

Ressalta-se que, nem toda demanda coletiva irá ser regrada pelo procedimento da Lei da Açáo Civil Pública, como exemplo, a açáo popular - Lei n.o 4.717/65, e a açáo de improbidade administrativa - Lei n. ${ }^{\circ}$ 8.429/92 que possuem regras próprias a fim de atender efetivamente às peculiaridades do direito material metaindividual. ${ }^{21}$ Rodolfo de Camargo Mancuso compartilha do mesmo entendimento no que se refere à natureza da Lei n. ${ }^{\circ}$ 7.347/95: predominantemente processual, ao considerar que esta visa oferecer os instrumentos processuais hábeis à efetivação, em juízo, da tutela aos interesses difusos (e acrescenta-se, direitos coletivos lato sensu) reconhecidos nos textos substantivos. ${ }^{22}$

Adota-se, neste trabalho, o entendimento de que, o procedimento da ação civil pública - "procedimento típico que oferta ferramentas processuais à tutela geral de direitos supra -individuais" ${ }^{23}$ - é especial.

\subsection{A ACP como procedimento especial: objeto tutelado, litígios coletivos e suas especificidades}

Após apontar o critério de identificaçáo de um procedimento especial utilizado neste artigo, bem como destacar a essênciadeste, identifica-se, aqui, a ação civil pública como um dos procedimentos especiais regulados externamente à legislação processual civil brasileira

\footnotetext{
21 RODRIGUES, M. A. Ação Civil Pública. In: Procedimentos especiais cíveis: legislação extravagante. Cristiano Chaves de Farias e Fredie Didier Jr. (coord.). 2003, p. 383.

22 MANCUSO, R. de C. Açáo Civil Pública e defesa do meio ambiente, do patrimônio cultural e dos consumidores. 2002, p. 32.

23 RODRIGUES, M. A. Açáo Civil Pública. In: Procedimentos especiais cíveis: legislação extravagante. Cristiano Chaves de Farias e Fredie Didier Jr. (coord.). 2003, p. 383.
} 
- Lei n. ${ }^{\circ} 13.105 / 2015$, exercendo esta uma função subsidiária ${ }^{24}$.

Trata-se, então, de um dos procedimentos especiais cíveis de jurisdição contenciosa, regulado por lei extravagante - Lei n. ${ }^{0}$ 7.347, de 24 de julho de 1985, a qual prevê um mecanismo processual peculiar para a prestação da tutela jurisdicional adequada. ${ }^{25}$

As especificidades da ação civil pública estão associadas, notadamente, ao objeto tutelado: direitos coletivos, difusos e individuais homogêneos, os chamados direitos coletivos lato sensu. Tais direitos não possuem titulares individuais determinados, uma vez que pertencem a uma comunidade ou coletividade, e dizem respeito a "conceitos interativos de direito material e processual, voltados para a instrumentalidade, para a adequação ao direito material da realidade hodierna e, dessa forma, para a sua proteçáo pelo Poder Judiciário". ${ }^{26}$

Ao partir deste entendimento, tendo por base o dispositivo legal - art. 81 do CDC - identificam-se como titulares o grupo de pessoas indeterminadas e ligadas por circunstância de fato (referente aos direitos difusos); o grupo, categoria ou classe de pessoas (referente aos direitos coletivos stricto sensu); e o grupo dos indivíduos que sofreram lesão de origem comum, tomados abstrata e genericamente para fins de tutela (referente aos direitos individuas homogêneos). ${ }^{27}$

No que se refere a estes direitos supra individuais, José Carlos Barbosa Moreira propôs uma classificação bipartida, e não tripartida, conforme previu o CDC, nos seguintes termos: essencialmente coletivos(direitos coletivos e difusos) e acidentalmente coletivos(direitos individuais homogêneos) ${ }^{28}$; o que, para Teori Albino Zavasck, estes corresponderiam à proteção coletiva de direitos e aqueles corresponderiam àproteção de direitos coletivos $^{29}$, considerando que, na defesa de direitos individuais homogêneos, embora a tutela seja indivisivelmente considerada, a divisibilidade é verificada nas fases de liquidação e execução da sentença coletiva.

\footnotetext{
24 Nesse sentido, destaca Juvêncio Vasconcelos Viana (Aspectos relevantes dos procedimentos especiais- Revista Dialética de Direito Processual Civil (RDDO), n. 26, maio, 2005, p. 78) a possibilidade de aplicaçáo subsidiária do procedimento-padráo nos procedimentos especiais, quando nesses faltarem regras específicas para o trato da situação.

25 Adotam este entendimento: MEDINA, José Miguel Garcia; ARAÚJO, Fábio Caldas de. José Miguel Garcia. et al (coords.) Processo civil moderno - Procedimentos cautelares e especiais, v. 4, São Paulo: Editora Revista dos Tribunais, 2009.; MARINONI, Luiz Guilherme. ARENHART, Sérgio Cruz. Procedimentos especiais. $3^{a}$ ed. rev. e atual. - São Paulo: Editora Revista dos Tribunais, 2012.; ORIONETE NETO, Luiz. "Teoria Geral dos procedimentos especiais". in Procedimentos especiais na legislação extravagante. São Paulo: Saraiva, 2003. Conforme destacam José Miguel Garcia e Fábio Caldas de Araújo (op. cit., p. 366), o objeto central da Lei de Ação Civil Pública (LACP - Lei n. ${ }^{0}$ 7.347/1985) reside na proteção dos interesses difusos e coletivos (e individuais homogêneos, nos termos do CDC).

26 DIDIER JR, F. ZANETI JR., H. Curso de Direito Processual Civil. Processo Coletivo, 2016, p. 78-79.

$27 \quad$ Ibidem., p. 79.

28 MOREIRA, J. C. B. M. Tutela jurisdicional dos interesses coletivos ou difusos, 1984, p. 197.

29 ZAVASCK, T. A. Reforma do processo coletivo: insdispensabilidade de disciplina diferenciada para direitos individuais homogêneos e para direitos transindividuais, 2007, p. 38.
} 
$\mathrm{Na}$ verdade, a classificação dos direitos coletivos lato sensu - em difusos, coletivos e individuais homogêneos - é inútil para a operacionalidade dos processos coletivos e da tutela dos direitos de grupo: "essa classificação é fruto de uma teorização artificial e abstrata realizada pela doutrina italiana quando, na década de setenta e oitenta, tentava compreender o fenômeno inédito das demandas coletivas norte-americanas" ${ }^{30}$, cuja doutrina, segundo ressalta Antonio Gidi, não menciona as expressōes "difusos", "coletivos", tampouco "individuais homogêneos".

Nesse sentido, verifica-se que o estudo da proteção dos direitos de grupo na doutrina brasileira, como na doutrina italiana, e diferente nas doutrinas francesa e alema $\tilde{a}^{31}$, volta-se essencialmente ao direito substantivo (direitos coletivos lato sensu), e não sob a perspectiva dos meios processuais para sua defesa em juízo.

A não utilidade, na prática, desta categorização dos direitos coletivos lato sensu é reconhecida, também, por Fredie Didier Jr. e Hermes Zaneti Jr.: "Nada obstante as diferenças entre os direitos coletivos, o processo coletivo é basicamente o mesmo, pouca importa o tipo de direito - ressalvada algumas peculiaridades." ${ }^{32}$

Verifica-se, então, a necessidade da adequação do processo/procedimento não em relação às categorizaçôes dos direitos transindividuais - já que, seja coletivo, difuso ou individual homogêneo, não há como diferenciar o procedimento -, mas, sim, além dos direitos transindividuais, como um todo, deve-se buscar a adequação do processo/procedimento às peculiaridades do caso levado a julgamento - os chamados litígios transindividuais, tese proposta por Edilson Vitorelli ${ }^{33}$, que abrange os litígios globais (aqueles que atingem à sociedade humana, representada pelo Estado nacional titular do território em que ocorreu a lesão), locais (que atingem a pessoas que integram uma sociedade altamente coesa, unida por laços de solidariedade social, emocional e territorial), e, por fim, os irradiados (que envolvem a lesão a direitos transindividuais que interessam, de modo diverso, a distintos segmentos sociais, caracterizado por alto grau de conflito). ${ }^{34}$

Nota-se, pois, a importância da especialidade do procedimento da ação civil pública: seja em razão da tutela dos direitos coletivos lato sensu, seja em razão da complexidade dos litígios coletivos. 2008, p. 202.

GIDI, A. Rumo a um Código de processo coletivo: a codificação das açôes coletivas do Brasil,

$31 \quad$ Ibidem., p. 202.

32 As peculiaridades que Fredie Didier Jr. e Hermes Zaneti Jr. (In: Curso de Direito Processual Civil. Processo Coletivo. V.4, 10 a ed., rev., ampl. e atual., Salvador: Editora JusPodivm, 2016, p. 83) ressaltam são aquelas relativas à publicaçáo de edital e à intervenção da vítima, do processo relativo aos direitos individuais homogêneos.

33 A soluçáo proposta por Edilson Vitorelli (In: Tipologia dos litígios transindividuais: um novo ponto de partida para a tutela coletiva. In: Zaneti Jr., Hermes (coord.). Processo coletivo. Salvador: Editora JusPodivm, 2016, p. 106) consiste na conceituação dos direitos transindividuais em três categorias, com base nas premissas teóricas sociológicas de Elliott e Tumer, atribuindo sua titularidade a uma sociedade que é formada sob o prisma de litígio transindividual, com o objetivo de proporcionar parâmetros para sua tutela jurídica.

34 VITORELLI, E. Tipologia dos litígios transindividuais: um novo ponto de partida para a tutela coletiva, 2016, p. 106. 
Pode-se afirmar que, as especificidades da ação civil pública correspondem aos institutos fundamentais do processo coletivo ${ }^{35}$, quais sejam: legitimaçáo(autônoma ${ }^{36}$ e concorrente aberta, múltipla, composta); representatitvidade adequada(onde deve prevalecer a seriedade e idoneidade por parte deste sujeito do contraditório); coisa julgada(erga omnes, por vezes secundum eventum litis); pedido e causa de pedir(referentes ao bem jurídico a ser tutelado - direitos coletivos lato sensu - e causa de pedir); conexão, continência e litispendência (limitadas ao pedido e a causa de pedir); preclusōes ${ }^{37}$; competências (as normas do microssistema brasileiro sobre a Açáo Civil Pública privilegiam o foro do local onde ocorreram os danos, originando competências concorrente, absoluta: competência territorial); ônus da prova(cabendo a prova dos fatos a quem tiver maior proximidade com eles e maior facilidade para demonstrá-los); liquidação da sentença(na qual a reparação dos danos individualmente sofridos - direitos individuais homogêneos - faz-se necessário apurar parte do debeatur - a existência do dano individualmente sofrido e o nexo causal com o dano geral reconhecido pela sentença coletiva condenatória); indenizaçáo pelos danos provocados(ou fluid reccovery, instituto típico das açóes coletivas que permite, em determinadas circunstâncias, que se passe do ressarcimento pelos danos sofridos à reparação dos danos provocados, caso o prejuízo individual ser inferior ou as vítimas forem de difícil identificação).

Além das especificidades acima elencadas, o procedimento da ação civil pública deve ser regido mediante a observância, por todos os sujeitos do processo, no âmbito da sua competência e colaboração no andamento da relaçáo jurídica processual, das normas fundamentais do processo civil, sejam regras, sejam princípios, objeto de análise do capítulo seguinte.

\section{AS NORMAS FUNDAMENTAIS E O NOVO CÓDIGO DE PROCESSO CIVIL}

No âmbito da ciência jurídica, ao ter como objeto de análise a "norma fundamental" em um determinado contexto, faz-se necessário, primeiramente, compreendê-la remetendose aos ensinamentos da Filosofia do Direito, da Teoria Geral do Direito, bem como às liçóes doutrinárias do Direito Constitucional.

\footnotetext{
35 GRINOVER, A. P. G. Direito Processual Coletivo, 2007, p. 33-35.

36 Para Fredie Didier Jr. e Hermes Zaneti Jr., tanto a legitimidade autônoma/extraordinária, como o instituto da coisa julgada náo dizem respeito à especificidade do processo coletivo. Quanto ao primeiro, a legislação prevê a legitimação extraordinária em outros casos (a exemplo, a ação coletiva ajuizada pela própria comunidade envolvida, os indígenas, previstas no Estatuto do Índio, mas com assistência do Ministério Público; quanto ao segundo, nem sempre a decisão que serve à tutela coletiva produzirá coisa julgada, a exemplo, do julgamento dos casos repetitivos - incidente que serve à tutela coletiva e náo produz coisa julgada (DIDIER JR, Fredie. ZANETI JR., Hermes. Curso de Direito Processual Civil. Processo Coletivo. V.4, 10a ed., rev., ampl. e atual., Salvador: Editora JusPodivm, 2016, p. 80).

37 Conforme destaca Ada Pellegrini Grinover (in GRINOVER, Ada Pellegrini Grinover. Direito Processual Coletivo. In: Teoria do processo: panorama doutrinário mundial. Eduaro Ferreira Jordão e Fredie Souza Didier Jr. (coord.) - Saçvador: JusPodivm, 2007, p. 34) o Anteprojeto do Código de Processo Coletivo permite a alteração do pedido e da causa de pedir até a sentença se feita de boa-fé e não hajaprejuízo para o demandado.
} 
A normaque é adjetivada como fundamentalno contexto do direito constitucional corresponde, na verdade, a um princípio constitucional ${ }^{38}$. Nesse sentido, conforme destaca o constitucionalista Paulo Bonavides, a juridicidade dos princípios constitucionais passa por três fases distintas ${ }^{39}$ : a jusnaturalista, a positivista e a pós-positivista.

$\mathrm{Na}$ primeira fase, os princípios habitam na esfera abstrata e sua normatividade, ainda praticamente nula, contrasta com o reconhecimento de sua dimensão ético-valorativa de ideia que inspira os postulados de justiça; na segunda - positivista - os princípios são inseridos nos Códigos como fonte normativa subsidiária, não sendo superior à lei, mas o seu complemento nos casos em que assim permitem: "[...] assinala Gordillo Cañas, os princípios entram nos Códigos unicamente como válvula de segurança, e náo como algo que se sobrepusesse à lei, ou lhe fosse anterior, senáo que, extraídos da mesma, foram ali introduzidos para estender sua eficácia de modo a impedir o vazio normativo." ${ }^{30}$; já na terceira fase - pós-positivista - os princípios são elevados à categoria primária, compondo um "pedestal normativo sobre o qual assenta todo o edifício jurídico dos novos sistemas constitucionais". ${ }^{41}$

Tanto regras quanto os princípios sáo normas, tratam de dizer o que deve ser: "Princípios sáo, tanto quanto as regras, razóes para juízos concretos de dever-se, ainda que de espécie muito diferente. A distinção [...] é, portanto, uma distinção entre duas espécies de normas." ${ }^{42}$

Dentre os critérios de distinção entre as espécies de normas em comento, destaca-se o critério da generalidade, ao considerar que, os princípios têm um grau de generalidade relativamente alto em relação ao grau de generalidade da norma. ${ }^{43}$

Os princípios são caracterizados como "mandamentos de otimização" ordenam que algo seja realizado na maior medida do possível dentro das possibilidades jurídicas e fáticas existentes; podem ser satisfeitos em graus variados e tal satisfação não depende tăo somente das possibilidades fáticas, mas das possibilidades jurídicas; já as regras equivalem à determinaçôesno âmbito daquilo que é fática e juridicamente possível.

\footnotetext{
38 Segundo Norberto Bobbio, os princípios gerais são normas fundamentais ou generalíssimas do sistema jurídico, as normas mais gerais: "O nome de princípios induz em engano, tanto que é velha questão entre juristas se os princípios são ou não normas. Para mim não há dúvida: os princípios gerais são normas como todas as demais. E esta é a tese sustentada também pelo estudioso que mais amplamente se ocupou da problemática, ou seja, Crisafulli." (apud Bonavides, Curso de Direito Constitucional, 2010, pp. 263 e 264). O constitucionalista José Afonso da Silva (Curso de Direito Constitucional Positivo, 2013, p.97), faz a distinção entre princípios constitucionais fundamentais e princípios gerais: os primeiros integram o Direito Constitucional positivo, traduzindo-se em normas fundamentais, normas-síntese ou normas-matriz; enquanto que os segundos envolvem conceitos gerais que integram a teoria geral do Direito Constitucional (dogmática jurídico-constitucional).
}

$39 \quad$ BONAVIDES, P. Curso de Direito Constitucional, 2011, p. 259.

40 BONAVIDES, P. Curso de Direito Constitucional, 2011, p. 262.

$41 \quad$ Ibidem., p. 264.

ALEXY, R. Teoria dos Direitos Fundamentais, 2015, p. 87.

$43 \quad$ Ibidem, Op., Cit., p. 87.

$44 \quad$ Ibidem, Op., Cit., p. 90. 
Enquanto os conflitos entre as regras ocorrem na dimensão da validade, as colisóes entre os princípios ocorrem na dimensão de peso, no sentido de que um deles tem precedência em face do outro sob determinadas condiçooes. Nesse sentido, a "norma fundamental" no Direito Constitucional Brasileiro corresponde a um princípio estabelecido na Constituição da República Federativa do Brasil de 1988 - princípios constitucionais fundamentais que integram o Direito Constitucional positivo -, sendo peculiar em razão da sua precípua função:

\begin{abstract}
normas-síntese ou normas-matriz cuja relevância consiste essencialmente na integraçáo das normas de que são súmulas, ou que desenvolvem, mas têm eficácia plena e aplicabilidade imediata, como as que contêm os princípios da soberania popular e da separação de poderes (arts. $1^{\circ}$, parágrafo único, e $\left.2^{\circ}\right) .^{45}$
\end{abstract}

Dessa forma, no contexto do Código de Processo Civil de 2015, entende-se por "norma fundamental" aquelas normas que são extraídas diretamente da Constituição Federal de 1988 - Direito Processual Fundamental Constitucional ${ }^{46}$-, bem como as normas previstas na própria legislação processual civil (arts. $1^{\circ}$ ao $12, \mathrm{CPC}$ ), que devem ser aplicados na relação jurídica processual a fim de se obter a devida tutela jurisdicional, traduzindo-se no devido processo legal, conforme se verifica no art. $1^{\circ}$ do CPC/2015: "O processo civil será ordenado, disciplinado e interpretado conforme os valores e as normas fundamentais estabelecidos na Constituição da República Federativa do Brasil, observando-se as disposiçôes deste Código.”

Ao contrário do CPC/73, o CPC/2015 consta, na Parte Geral, um Livro reservado para disposição das "normas fundamentais e da aplicação das normas processuais", tratando o capítulo I "das normas fundamentais do processo civil".

Dentre elas, estão as normas-princípios: art. $4^{\circ}, \mathrm{CPC} / 2015$, que corresponde ao princípio da primazia da decisão de mérito, o art. $6^{\circ}, \mathrm{CPC} / 2015$ e o art. $8^{\circ}, \mathrm{CPC} / 2015$, que correspondem ao princípio constitucional da razoabilidade do processo, previsto no inciso LXXVIII, do art.5 $5^{\circ} \mathrm{CF} / 1988$, bem como ao princípio do devido legal, previsto no inciso LIV, art. $5^{\circ}, \mathrm{CF} / 1988$, de modo a englobar, na verdade, todos os demais princípios que devem nortear a relaçáo jurídica processual, correspondendo, pois, aos seguintes aqui identificados; o art. 5 , CPC/2015, que corresponde ao princípio da boa-fé processual, incluindo a atuaçáo de todos os sujeitos processuais, não somente o autor e réu; os arts. $7^{\circ}, 9^{\circ}$ e $10 \mathrm{CPC} / 2015$ que correspondem ao princípio do contraditório, previsto no

\footnotetext{
$45 \quad$ AFONSO, J. da S. Curso de Direito Constitucional Positivo, 2013, p. 98.

46 DIDIER JUNIOR, F. Curso de Direito Processual Civil: introdução ao direito processual civil, parte geral e processo de conhecimento, 2015, p 62.
} 
inciso LV, art. 5 $\mathrm{CF} / 1988$, e o art. 11, CPC/2015, que corresponde ao princípio da motivação das decisóes judiciais (bem como administrativas), previsto no inciso IX e X, do art. 93, CF/1988.

Verifica-se que, o que as distingue das demais normas previstas do CPC/2015, é a sua função, qual seja, nortear a relação jurídica processual (ordenando, disciplinando e interpretando o processo), sendo que a sua náo observância e, consequentemente, a sua não aplicação, resultará em um processo inválido à luz tanto da Constituição Federal, quanto do Código de Processo Civil, haja vista a ausência de um devido processo legal. Conforme bem destaca José Joaquim Gomes Canotilho:

O problema nuclear da exigência de um due process não estaria tanto - ou pelo menos não estaria exclusivamente - no procedimento legal mediante o qual alguém é declarado culpado e castigado ("privado da vida, da liberdade e da propriedade”) por haver violado a lei, mas sim no facto de a lei poder ela própria transportar a "injustiça" privando uma pessoa de direitos fundamentais. ${ }^{47}$

As normas fundamentais no contexto do $\mathrm{CPC} / 2015$, portanto, têm a função de ordenar, disciplinar e interpretar a relaçáo jurídica processual com o precípuo objetivo de garantir os direitos fundamentais, tanto previstos na Lei Maior, quanto na legislação infraconstitucional, daqueles que compóem essa relaçáo, sobretudo, das partes, que discutem no processo os seus direitos com o fito de obter a devida tutela jurisdicional, uma proteção jurídica eficaz e temporalmente adequada.

A norma é fundamental pois, conforme bem destaca Fredie Didier $\mathrm{Jr}^{48}{ }^{48}$, estrutura o modelo do processo civil nacional e serve de diretriz para a compreensão de todas as demais normas jurídicas aplicadas à relação jurídica processual, ora princípios, ora regras, inclusive que não estáo somente concentradas nos doze primeiros artigos do CPC/2015, mas em outros dispositivos, a exemplo dos art. 190: "Versando o processo sobre direitos que admitam autocomposição, é lícito às partes plenamente capazes estipular mudanças no procedimento para ajustá-lo às especificidades da causa e convencionar sobre os seus ônus, poderes, faculdades e deveres processuais, antes ou durante o processo.”

Esta regra prevista na legislação infraconstitucional, embora não esteja prevista na Parte Geral, Livro I, Título Único, Capítulo I do novo código de processo civil ${ }^{49}$, tampouco prevista ipsis litteris no texto constitucional, é considerada norma fundamental, uma vez que se trata de uma das garantias fundamentais destinada às partes do processo, qual seja: possibilidade de se valer do sistema autocompositivo, resolvendo o seu conflito de forma consensual.

\footnotetext{
47 CANOTILHO, J. J. G. Curso de Direito Constitucional, 1993, p. 494.

48 DIDIER JUNIOR, F. Curso de Direito Processual Civil: introdução ao direito processual civil, parte geral e processo de conhecimento, 2015, p. 61.

49 O Livro I do Novo Código de Processo Civil trata das Normas Processuais Civis, cujo Título Único é "Das Normas Fundamentais do Processo Civil" e o Capítulo I: "Das Normas Fundamentais do Processo Civil": arts. $1^{\circ}$ ao 12 .
} 


\subsection{A natureza jurídica das normas fundamentais}

As normas fundamentais constantes na legislação infraconstitucional 13.105/2015, que tratam dos direitos e garantias fundamentais atinentes ao processo judicial, têm natureza jurídica de normas-princípios, respaldadas na Constituição; a priori, na medida em que não haja colisão entre tais normas, têm eficácia e aplicabilidade imediata, conforme se depreende da leitura do parágrafo $1^{\circ}$, art. 5, $\mathrm{CF} / 1988$ : "as normas definidoras dos direitos e garantias fundamentais têm aplicação imediata".

Acerca desta aplicação no que se refere à efetividade dos direitos, José Afonso da Silva ressalta que, em regra, as normas que consubstanciam os direitos fundamentais democráticos e individuais são de eficácia imediata, enquanto as que definem os direitos econômicos e sociais tendem a sê-lo também na Constituição vigente, mas, algumas, especialmente as que mencionam uma lei integradora, são de eficácia limitada, de princípios programáticos e de aplicabilidade indireta, embora sejam tão jurídicas como as outras e exercem relevante função. ${ }^{50}$

Há que considerar a concepção que, ao invés de destacar o direito invocado, destaca o sujeito da obrigação e as suas condicionalidades - considera que a escassez é uma realidade sempre presente ${ }^{51}$-, chamada concepção subjetivista ou relativista: a efetividade de algum dos direitos fundamentais está sujeito à ponderação na hipótese de colisão no caso concreto.

No que diz respeito à aplicação das normas-princípios atinentes ao processo - devido processo legal, contraditório, ampla defesa, duração razoável do processo, igualdade processual (paridade de armas), eficiência, boa-fé processual, efetividade, adequação (legal jurisdicional e negocial), cooperação, primazia da decisão de mérito -, estas têm a precípua função de ordenar e disciplinar toda relação jurídica processual.

As normas do CPC/2015 que reproduzem o texto constitucional têm, pois, eficácia plena e imediata por se tratarem de direitos e garantias fundamentais referentes ao andamento regular e devido da relação jurídica processual, salvo ao verificar alguma colisão no caso concreto, hipótese esta, inclusive, prevista no código, por exemplo: parágrafo único do artigo 11 (segredo de justiça), no que tange ao princípio da publicidade e o inciso I (tutela provisória de urgência) do artigo $9^{\circ}$, no que tange ao princípio do contraditório e da ampla defesa.

Conforme abordado anteriormente, as normas fundamentais do processo civil correspondem tanto a princípios (Direito Processual Fundamental Constitucional), quanto a regras (previstas na própria legislaçáo processual, inclusive, não somente nos primeiros doze artigos do Código, que compóem a Parte Geral - Das Normas Fundamentais, mas em outros dispositivos dispersos na lei processual, a exemplo: o princípio do autorregramento da vontade no processo e o dever de observância aos precedentes judiciais.

\footnotetext{
50 SILVA, J. A. da. Curso de Direito Constitucional Positivo, 2005, p. 180.

51 BAHIA, S. J. C. Judicializaçáo da política, 2014, p. 399.
} 
Vale ressaltar que, segundo entendimento de Fredie Didier Jr., existem normas fundamentais do processo civil que não possuem status de direitos fundamentais, como as regras decorrentes do art. $2^{\circ}$, que diz respeito à iniciativa da parte e o impulso oficial referente à origem e o desenvolvimento do processo, respectivamente; e art. 12, que se refere à observância da ordem cronológica de conclusão para proferir sentença ou acórdão. Não obstante, há de se considerar que ambas as regras estão pautadas em direitos e garantias fundamentais atinentes à relação jurídica processual, seja o direito à ação, seja o direito à inafastabilidade da jurisdição.

Interessa-nos, neste trabalho, tratar da efetividade, no âmbito da ação civil pública, das normas fundamentais que estão previstas no Capítulo I, do Titulo Único do Livro I da Parte Geral do CPC/2015, especificamente os artigos 30 ao 11, princípios dotados de força normativa.

\subsection{A teoria da força normativa dos princípios e o Novo Código de Processo Civil}

A Teoria da Força Normativa dos princípios consiste, em uma breve síntese, em reconhecer estes como norma: "os princípios são normas e as normas compreendem igualmente os princípios e as regras”, assim discutido e entendido por Robert Alexy, Ronald Dworkin e Crisafulli. ${ }^{52}$ Destaca o constitucionalista Paulo Bonavides, embasando-se nas liçóes do jurista Joseph Esser, que, caso os princípios não cheguem ser, a rigor, uma norma no sentido técnico da palavra, os princípios, como ratio legis, são possivelmente Direito Positivo, que pelos veículos interpretativos se exprimem, e assim se transformam numa esfera mais concreta.

O princípio normativo deixa de ser ratio legis e passa a ser a própria lex, integrando, assim, a parte constitutiva das normas jurídicas, pertencendo ao Direito Positivo, dividindo-se em duas categorias: aqueles que assumem o caráter de ideias jurídicas norteadoras, postulando concretização na lei e na jurisprudência; e aqueles que, não sendo apenas ratio lex, mas também lex, cristaliza numa regra jurídica de aplicação imediata. ${ }^{53}$

Dessa forma, da análise do capítulo I do título único do Livro I da Parte Geral do CPC, do art. 140 e do art. 489, $\$ 2^{\circ}$, CPC, verifica-se que a Teoria da força normativa dos princípios ganhou notoriedade na nova legislação processual civil, onde normas fundamentais (princípios) constitucionais são reproduzidos integralmente no texto da legislação, ou, se não reproduzidas, embasam as demais normas (regras) dispersas no CPC, incluindo uma parte exclusiva a tais normas - Das Normas Fundamentais e da aplicação das normas processuais.

É dever do Estado-juiz, ao se deparar com a omissão do ordenamento jurídico (que se revelam na lacuna ou obscuridade), decidir o caso de acordo com a analogia, os costumes

\footnotetext{
52 BONAVIDES, P. Curso de Direito Constitucional, 2011, p. 271.

53 Segundo Larenz (apud Bonavides, Op. Cit., 2011, p. 272), os princípios que correspondem à primeira categoria, desprovidos do caráter de norma, são princípios "abertos" (offene Prinzipien) e o que correspondem á segunda categoria se apresentam como "princípios normativos".
} 
e aos princípios gerais do direito (art. 4\% , LINB), e não se eximir da sua função sob o argumento da omissão da ordem jurídica, conforme prevê o art. 140, CPC/2015.

Ademais, essa influência da Teoria Normativa dos Princípios no CPC/2015 também se verifica na análise do art. $489, \$ 2^{\circ}$, que dispóe: "No caso de colisão entre normas, o juiz deve justificar o objeto e os critérios gerais da ponderação efetuada, enunciando as razóes que autorizam a interferência na norma afastada e as premissas fáticas que fundamentam a conclusão.”

Nota-se que o termo empregado "normas" refere-se tanto a regras, quanto aos princípios, sobretudo estes quando o legislador menciona o critério da "ponderação" em caso de colisão entre as normas. Nesse sentido, Robert Alexy defende a ponderação como modelo de fundamentação, assegurando a sua racionalidade, caracterizado pela maximização dos princípios sem invalidar um deles, ao contrário, pois, do que ocorre quando há colisão entre as regras: "[...] nos casos concretos, os princípios têm pesos diferentes e que os princípios com o maior peso têm precedência." 54

Enquanto que os conflitos entre regras ocorrem na dimensão da validade, as colisōes entre princípios ocorrem na "dimensão do peso" 55 - o qual é identificado recorrendo-se ao critério da ponderação.

\section{OS LITÍGIOS COLETIVOS E A EFETIVIDADE DAS NORMAS FUNDAMEN- TAIS DO PROCESSO CIVIL}

Buscar a efetividade das normas fundamentais do processo civil é buscar a garantia de um devido processo legal; é buscar a concretização da justiça. Conforme destaca José Joaquim Gomes Canotilho, a justiça concretiza-se através de princípios jurídicos materiais "cujo denominador comum se reconduz à afirmação e respeito da dignidade da pessoa humana, à proteção da liberdade e desenvolvimento da personalidade e à realização da igualdade" 56 .

Em verdade, do postulado da dignidade da pessoa humana decorrem, além de princípios formais, "outros princípios materiais, que se referem às condiçóes substanciais de cuja satisfação depende a garantia da dignidade humana" ${ }^{57} \mathrm{O}$ referido postulado jurídico constitucional tem, pois, não somente a função de sustentar determinado princípio, mas também complementá-lo.

Dessa forma, na medida em que os direitos fundamentais são protegidos e efetivados pelo Estado na solução dos litígios levados ao Estado-juiz, consequentemente, o postulado da dignidade da pessoa humana está sendo afirmado e respeitado.

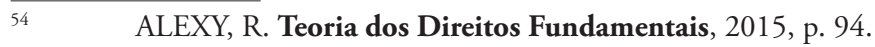

55 Ibdem, Op. Cit., p. 94.

56 CANOTILHO, J. J. G. Curso de Direito Constitucional, 1993, p. 245.

57 ALEXY, R. Teoria dos direitos fundamentais, 2015, p. 358.
} 
No caso da solução dos litígios coletivos não seria diferente, sendo de extrema importância, portanto, à observância, pelo Estado-juiz, a começar, da norma fundamental estabelecida no artigo $8^{\circ}$ do CPC/2015, no qual impóe a este o dever de resguardar e promover a dignidade da pessoa humana. Afinal, conforme Daniel Sarmento destaca, a dignidade humana compreende o direito de acesso às necessidades materiais básicas de vida, pressuposto para o pleno exercício das liberdades civis e da democracia. ${ }^{58}$

Ressalte-se que a tutela coletiva acaba por ser o cenário propício para que se efetive o acesso às necessidades materiais básicas a um determinado número de indivíduos, de modo a refletir os interesses sociais, cabendo não tão somente ao Estado-juiz promover esta efetividade, mas às demais instituiçóes públicas, com destaque para Defensoria Pública, instituição que se coaduana, por excelência, ao paradigma do neoconstiucionalismo ao exercer, sobretudo, a promoção dos direitos humanos e a defesa dos direitos coletivos dos necessitados, em todos os graus, de forma integral e gratuita, como expressão e instrumento do regime democrático. ${ }^{59}$

Analisemos, então, as normas fundamentais que devem, obrigatoriamente, serem observadas e aplicadas pelos envolvidos na relação jurídica processual à luz das particularidades da ação civil pública.

Ao partir da norma fundamental que diz respeito à primazia da decisão de mérito justa e efetiva, tendo as partes o direito de obter, em prazo razoável, a solução integral do mérito, incluída a atividade satisfativa - artigos $4^{\circ}$ e $6^{\circ}$ do CPC/2015 -, ou daquela que diz respeito à vedação da decisão surpresa, no sentido de que o juiz, em qualquer grau de jurisdição, não pode decidir com base em fundamento a respeito do qual não se tenha dado às partes a oportunidade de se manifestar - artigo 10 do CPC/2015 -, vê-se o quão é importante concretizá-las de modo peculiar para solucionar o litígio coletivo, uma vez que o interesse não é de um só indivíduo.

No que diz respeito à solução integral do mérito, pode-se admitir, por exemplo, várias possibilidades de tutela (solução) quando uma lesão atingir de diferentes formas os indivíduos que compóem uma sociedade. ${ }^{60}$ Nestes casos, a atividade satisfativa deverá atender às necessidades do caso concreto, de modo a corresponder à tutela adequada para cada situação correspondente.

\footnotetext{
58 SARMENTO, D. Dignidade da pessoa humana: conteúdo, trajetórias e metodologia, 2016, p. 239.

59 Conforme bem destacado por Tiago Fensterseifer, a Emenda Constitucional n. ${ }^{\text {o }} 80 / 2014$ assegurou importante suporte normativo para a legitimidade da Defensoria Pública para o ajuizamento de ação civil pública, entre outras medidas processuais e extraprocessuais de natureza coletiva, de modo a fortalecer o regime constitucional da instituição inaugurado pela Emenda Constitucional 45/2004 (Reforma do Judiciário) In: Defensoria Pública, proteção ambiental e Novo Código de Processo Civil., Coleção Repercussōes do Novo CPC - Processo Coletivo, ZANETI JR, Hermes (coord.), Salvador:Juspodivm, 2016, p. 446). Atribuição da DP prevista no art. 134, CF/1988., e inclusão de título próprio no NCPC, art. 185 - TítuloVII - Da Defensoria Pública.

60 Edilson Vitorelli (In: Tipologia dos litígios transindividuais: um novo ponto de partida para a tutela coletiva, p. 88) identifica que, via de regra, lesóes graves atingem os indivíduos de modos variados, acarretando potencial de conflito entre os envolvidos.
} 
Já no que diz respeito à oportunidade do efetivo contraditório e à participação das partes no âmbito do litígio coletivo - artigos $7^{\circ}, 9^{\circ}$ e 10 do $\mathrm{CPC} / 2015$, há de se considerar e valorizar uma das especificidades do procedimento da ação civil pública: a representatividade adequada. Entende por esta como uma "qualidade apresentada pelo representante que atuará em nome da sociedade ou do grupo na defesa de interesses de ordem coletiva" ${ }^{\text {, }}$, que abrange uma defesa eficiente dos interesses coletivos.

Há de considerar que esse representante será o porta-voz dos cidadãos, da comunidade, de um determinado grupo - titulares de determinados direitos, e, que deve ser, de fato, adequado para que haja o efetivo contraditório, bem como haja o efetivo exercício de direitos e faculdades processuais.

Entretanto, isso náo impede que náo haja a participaçáo efetiva daqueles diretamente afetados; daí a importância das audiências públicas em litígios coletivos, instrumento que não tâo somente concretiza a democracia participativa, mas a própria solução do litígio, no sentido de que a "participação deixa de ser apenas indicativo de justa possibilidade de manifestação para configurar colaboração para uma solução justa" . ${ }^{62}$

No âmbito do procedimento da ação civil pública também é inquestionável a observância da norma fundamental que diz respeito ao comportamento pautado na boa-fé - art. $5^{\circ}$ do $\mathrm{CPC} / 2015$ - de todos aqueles que participam do processo, inclusive, de modo a cooperar entre si a fim de alcançar a soluçáo justa e efetiva, bem como a norma fundamental que diz respeito à motivação de todos os julgamentos dos órgãos do Pode Judiciário - artigo 11 do CPC/2015 -, extraída do inciso IX, do artigo 93 da Constituição Federal de 1988, e, por fim, a que diz respeito à solução consensual do conflito - artigo $3^{\circ}$, parágrafos $2^{\circ}$ e $3^{\circ}$.

No tocante a este último quesito, não há nenhum dispositivo que trata expressamente da possibilidade da autocomposição no curso do procedimento na Lei da Ação Civil Públi$\mathrm{ca}^{63}$, no entanto, trata-se de uma técnica processual compatível ao referido procedimento, no qual a figura do representante adequado, mais uma vez, mostra-se de fundamental relevância, a partir do momento em que poderá verificar possibilidades viáveis e favoráveis para conciliar ou mediar com a parte contrária, ou, até mesmo, durante a participação social - audiências públicas - garantindo, assim, a tutela dos direitos coletivos afetados.

\section{CONCLUSÃO}

O novo código de processo civil brasileiro foi elaborado e publicado em regime democrático, na contemporaneidade, onde os litígios coletivos estáo cada vez mais presentes; onde as demandas de ordem social são frequentes, e a tutela jurisdicional cada vez mais

\footnotetext{
${ }_{61}$ FORNACIARI, F. H. C. F. Representatividade adequada nos processos coletivos. 2010, p. 50.

62 CABRAL, A. P. O contraditório como dever e a boa-fé processual objetiva, 2005, p. 65-67.

63 GAVRONSKI, A. Autocomposiçáo no novo CPC e nas açóes coletivas, 2016.
} 
necessária e urgente, haja vista a omissão no que diz respeito ao planejamento e execução das políticas públicas.

Neste cenário contemporâneo, no qual a realidade da tutela coletiva mostra-se relevante e eficaz, não se pode pensar em um Judiciário que efetive direitos fundamentais, tais como saúde e educação, em um processo civil clássico ou tradicional, destinado a um único vencedor, de modo a excluir aqueles que náo tiveram o acesso à justiça de imediato e com meios propícios que os facilitassem para isto, embora se encontrem na mesma situação fática que aquele.

Em que pese não haver nenhuma parte, ou sequer, um capítulo neste novo diploma processual com a função de disciplinar o processo coletivo, com ênfase ao procedimento da ação civil pública, pode-se afirmar que a observância e a aplicação das normas fundamentais elencadas na Parte Geral, Capítulo I, são de extrema importância para o devido processo coletivo na medida em que se trate de adequar às especificidades de tal procedimento, sobretudo, no que tange à representatividade adequada por todos os envolvidos na relaçáo jurídica processual apresentada.

De fato, tem-se como a ação civil pública um procedimento especial em decorrência não táo somente dos direitos coletivos latu sensu que tem como objeto de tutela, mas também, em razão dos diversos tipos de litígios coletivos que vem ocorrendo na sociedade contemporânea. Assim, as normas cabíveis no âmbito da açáo civil pública, devem ser devidamente efetivadas de acordo com as peculiaridades do referido procedimento, sobretudo no que se refere às normas fundamentais do processo civil pátrio.

Não somente cabe ao Estado-juiz observar e aplicar tais normas fundamentais, mas também as demais instituiçóes públicas e partes envolvidas na relação jurídica processual, como a Defensoria Pública, instituição esta que tem título próprio no NCPC e que retrata o constitucionalismo social ao buscar a promoção dos direitos fundamentais mediante a ação civil pública daqueles que se encontram em situaçáo vulnerável, de modo a inseri -los como reais integrantes de uma nação, de uma sociedade.

\section{REFERÊNCIAS}

AFONSO, J. da S. Curso de Direito Constitucional Positivo. Ed. 36º ver, atual, São Paulo, Editora Malheiros, 2013, p. 98.

ALEXY, R. Teoria dos direitos fundamentais. Tradução de Virgílio Afonso da Sailva, ed. 4a , São Paulo: Editora Malheiros, 2015.

BAHIA, S. J. C. Judicializaçáo da política. Em II Jornada de direito constitucional / Tribunal Regional Federal da 1a Região, Escola de Magistratura Federal da $1^{\text {a }}$ Região Brasília: ESMAF, 2014.

BONAVIDES, P. Curso de Direito Constitucional. ed. 26a , São Paulo: Editora Malheiros, 2011. 
BRAGA, P. S. Norma de processo e norma de procedimento - o problema da repartição de competência legislativa no Direito constitucional brasileiro, $1^{\text {a }}$ ed., Salvador: Editora JusPodivm, 2015.

CABRAL, A. P. O contraditório como dever e a boa-fé processual objetiva. Repro, n. ${ }^{\circ}$ 126, São Paulo: RT, p. 65-67, ago., 2005.

CANOTILHO, J. J. G. Curso de Direito Constitucional. ed. 6a, Livraria Almeida, Coimbra, 1993.

DIDIER JR., F. Curso de Direito Processual Civil: introdução ao direito processual civil, parte geral e processo de conhecimento. 17. Ed. - Salvador: JusPodivm, 2015.

DIDIER JR, F. e ZANETI JR., H. Curso de Direito Processual Civil, vol. 4, 10a ed., rev., ampl. e atual., Salvador: Editora Juspodivm, 2016.

DINAMARCO, C. R. A instrumentalidade do processo, vol. 1, 3a ed., rev. e atual, São Paulo: Editora Malheiros, 1993.

FAZZALARI, E. Instituzioni di Diritto Processuale. 8ª ed. Padova: CEDAM, 1996.

FENSTERSEIFER, T. Defensoria Pública, proteçáo ambiental e novo Código de Processo Civil. In: Coleçáo Repercussóes no Novo CPC - Processo Coletivo, v. 8/coord. Hermes Zaneti Jr.; coord. Geral, Fredei Didier Jr. - Salvador: Juspodivm, 2016.

FORNACIARI, F. H. C. F. Representatividade adequada nos processos coletivos. 2010. Tese (Doutorado em Direito) - Faculdade de Direito da Universidade de Sáo Paulo, Sáo Paulo, 2010.

GAVRONSKI, A. Autocomposição no novo CPC e nas açóes coletivas. Coleção Repercussóes do Novo CPC. Coord. Hermes Zaneti Jr. Salvador: Juspodivm, 2016.

GIDI, A. Rumo a um Código de processo coletivo: a codificaçáo das açóes coletivas do Brasil. - Rio de Janeiro: Editora Forense, 2008.

GRINOVER, A. P. G. Direito Processual Coletivo. In: Teoria do processo: panorama doutrinário mundial. Eduaro Ferreira Jordão e Fredie Souza Didier Jr. (coord.) - Saçvador: JusPodivm, 2007.

MANCUSO, R. de C. Açáo Civil Pública e defesa do meio ambiente, do patrimônio cultural e dos consumidores. $9^{a}$ ed., rev. e atual., São Paulo: Editora Revista dos Tribunais Ltda., 2002.

MARCATO, A. C. Procedimentos especiais. $8^{a}$ ed., rev., atual. e ampl. São Paulo: Malheiros Editores, 1994.

MARINONI, L. G. ARENHART, S. C. Procedimentos especiais. $3^{a}$ ed. rev. e atual. São Paulo: Editora Revista dos Tribunais, 2012. 
MEDINA, J. M. G.; ARAÚJO, F. C. de. Processo civil moderno - Procedimentos cautelares e especiais, v. 4, São Paulo: Editora Revista dos Tribunais, 2009.

MOREIRA, J. C. B. M. Tutela jurisdicional dos interesses coletivos ou difusos In: Temas de Direito Processual, 3a série, São Paulo: Editora Saraiva, 1984.

PASSOS, J. J. C. Teoria geral dos procedimentos especiais. Procedimentos especiais na legislação extravagante. São Paulo: Saraiva, 2003.

RODRIGUES, M. A. Ação Civil Pública. In: Procedimentos especiais cíveis: legislação extravagante. Cristiano Chaves de Farias e Fredie Didier Jr. (coords.). São Paulo: Saraiva, 2003.

SARMENTO, D. Dignidade da pessoa humana: conteúdo, trajetórias e metodologia. Belo Horizonte: Fórum, 2016.

SILVA, J. A. da. Curso de Direito Constitucional Positivo. Ed. 36a , ver., atual., São Paulo: Editora Malheiros, 2013.

THEODORO JR., H. Curso de Direito Processual Civil. vol. II - Procedimentos especiais., 50ª ed., rev., atual. e ampl., Rio de Janeiro: Editora Forense, 2016.

VIANA, J. V. Aspectos relevantes dos procedimentos especiais. Revista Dialética de Direito Processual Civil (RDDO), n. 26, maio, 2005.

VITORELLI, E. “Tipologia dos litígios transindividuais: um novo ponto de partida para a tutela coletiva. In: Zaneti Jr., Hermes (coord.). Processo coletivo. Salvador: Editora JusPodivm, 2016.

WAMBIER, L. R. Sentença Civil: Liquidação e Cumprimento. 3 ed. São Paulo: Revista dos Tribunais, 2006.

ZAVASCK, T. A. Reforma do processo coletivo: insdispensabilidade de disciplina diferenciada para direitos individuais homogêneos e para direitos transindividuais. In: Grinover, Menes e Watanabe (coord.), Direito Processual Coletivo e o anteprojeto de Código Brasileiro de Processos Coletivos, São Paulo: RT, 2007. 